Pesquisa e Reflexão em Educação Básica

\title{
Construção de um website institucional: um estudo de caso baseado em critérios de navegação, design e ergonomia
}

Eliane de Oliveira Borges ${ }^{1}$

Patricia Alejandra Behar ${ }^{2}$

\begin{abstract}
Resumo:
Este artigo apresenta o processo de construção da primeira versão (2008) do website institucional para a Escola Técnica Estadual Senador Ernesto Dornelles, cujos componentes e organização básica são mantidos até hoje. Este website foi criado com o objetivo de servir como apoio na divulgação e informação sobre os cursos oferecidos, atividades, eventos e outras inferências importantes para a sua comunidade. 0 website foi idealizado com uma interface amigável, com imagens, textos, links etc. A concepção foi baseada em bibliografia pertinente e referente ao design, à navegação e à ergonomia. No planejamento do website, foram evidenciados o material fotográfico que documenta a arquitetura da Escola e as cores do prédio. Como resultado da pesquisa realizada com a comunidade escolar, o website teve uma boa aceitação e encontra-se em sua terceira versão e está sendo amplamente utilizado pela comunidade escolar.
\end{abstract}

\section{Palavras-chave: \\ Website institucional. Escolas técnicas e públicas. Design. Navegação. Ergonomia. \\ Construction of an institutional website: a case study based on navigation criteria, design and ergonomics}

\begin{abstract}
:
This article presents the conceiving of the first version (2008) of the institutional website for Technical School State Senator Ernesto Dornelles, whose components and basic organization are maintained to this day. This website was created with the objective to serve as support for dissemination and information on available courses, activities, events and other important inferences to their community. The page was designed with a friendly interface, with images, text, links etc. The conception was based on literature and concerning the design, navigation and ergonomics. In the planning of
\end{abstract}

1 Doutora em Ciências Biológicas pela Universidade Federal do Paraná. Professora de Biologia do Colégio Estadual Júlio de Castilhos (2007). E-mail: eliane.borges@ufrgs.br. ORCID iD: https://orcid.org/0000-0001-9869-0860

2 Doutora em Ciência da Computação pela Universidade Federal do Rio Grande do Sul. Professora Titular da Faculdade de Educação e dos Cursos de Pós-Graduação em Educação (PPGEdu) e em Informática na Educação (PPGIE) da Universidade Federal do Rio Grande do Sul. E-mail: pbehar@terra.com.br. ORCID iD: https://orcid.org/0000-0001-6939-5678 
the website, the photographic material that documents the architecture of the school and the colors of the building were highlighted. As a result of research conducted with the school community, the website had a good acceptance and it is now in this third version and is widely used by their members.

\section{Keywords:}

Institutional website. Technical and public schools. Design. Navigation. Ergonomics.

\section{Construcción de un sitio web institucional: un estudio de caso basado en criterios de navegación, diseño y ergonomia}

\section{Resumen:}

Este artículo presenta el proceso de construcción de la primera versión (2008) del sitio web para la Escola Técnica Senador Ernesto Dornelles, cuyos componentes y la organización básica son mantenidos hasta el día de hoy. Este sitio web fue creado con el objetivo de servir como apoyo en la difusión e información sobre los cursos ofrecidos, actividades, eventos y otras inferencias importante para su comunidad. El sitio web fue diseñado con una interfaz amigable, con imágenes, textos, enlaces, etc. La concepción se basó en bibliografía pertinente y referentes al diseño, navegación y ergonomía. En la planificación del sitio web se destacó el material fotográfico que documenta la arquitectura de la Escuela y los colores del edificio. Como resultado de la investigación realizada con la comunidad escolar, el sitio web fue bien aceptado y se encuentra en su tercera versión y está siendo ampliamente utilizado por la comunidad escolar.

\section{Palabras clave:}

Sitio web institucional. Escuelas técnicas y públicas. Diseño. Navegación. Ergonomía.

\section{Introdução}

A Escola Técnica Estadual Senador Ernesto Dornelles (ETESED) atende alunos do Ensino Médio e do Ensino Técnico em Design de Interiores, Nutrição e Dietética e de Prótese Dentária. Possui alunos com diferentes perfis: o público adolescente e o público adulto, que geralmente trabalha e já constituiu sua própria família. Suas instalações nos remetem ao ano de 1914, com uma arquitetura exuberante. O prédio, originalmente uma escola de ensino fundamental, foi destinado, em 1946, ao ensino profissionalizante feminino (BORGES, 2008).

A partir da solicitação de construção do website da Escola, procurou-se agregar a comunidade, já que a ferramenta encerra em si mesma a possibilidade de atenuar possíveis arestas acerca da sua compreensão e utilidade, através da utilização de estratégias afetivas como: homenagens aos membros da comunidade, lembretes sociais, datas comemorativas, valorização de feitos etc. (BORGES, 2008).

De acordo com a Teoria Sócio-Histórica de Vygotsky, é através da convivência com o outro, na vivência das diferenças, através da interação social com outros mais experimentados, é que se dará a aprendizagem dos usuários pouco habilitados. Estes, com a formação da ZDP - Zona de desenvolvimento proximal -, adquirem as habilidades necessárias para o uso da ferramenta (VYGOTSKY, 1998). E, foi pensando nesta interação social que se procurou criar uma interface simples, onde o usuário pudesse navegar através de links de fácil identificação e, que o remetesse ao ambiente escolar. Assim se buscou, na bibliografia, as opiniões necessárias ao seu desenvolvimento. 
A seleção do conteúdo obedeceu aos critérios adotados por Nascimento (2008), com levantamentos sobre as características dos usuários e da instituição. A partir daí pôde-se chegar à base de interesse da instituição e dos seus componentes. Assim elencou-se características de qualidade, sob enfoque dos critérios de navegação, design e ergonomia do website escolar que seriam provavelmente utilizadas no website.

A navegação, por definição, orienta o usuário no deslocamento através dos hyperlinks da página inicial e das páginas que o constituem. Para isso existem as técnicas de sinalização através de títulos, ícones, menus... (NASCIMENTO, 2008). Também se espera que organize adequadamente a quantidade de informação que deverá aparecer na tela do computador, garanta a atenção do usuário e não o sobrecarregue com informações desnecessárias. Além de não mostrar as informações todas de uma vez, apresentar apenas o que for relevante para o usuário naquele momento e, apresentar uma sequência lógica de informações necessárias (NASCIMENTO, 2008).

O design, como um esforço criativo relacionado à configuração, concepção, elaboração e especificação de um artefato, caracteriza-se por ser um esforço normalmente orientado por uma intenção ou objetivo, ou para a solução de um problema (VASCONCELOS FILHO, 2010). São características desejáveis na interface de um website: que seja consistente e agradável do ponto de vista estético, que estimule a curiosidade dos usuários, cause boas primeiras impressões, que apresente a informação de forma organizada, que ajude o usuário no seu processo de aprendizagem. Sabe-se que a utilização de cores pode-se dar de acordo com diferentes propósitos, como ferramenta de navegação, estabelecendo o "tom" de um site (mais informal, mais alegre, ou mais elegante e formal etc.), desviando a atenção do usuário dos objetivos anteriormente traçados, agrupando ou relacionando informações e atraindo atenção para onde se deseja. Portanto, as mesmas não devem ser utilizadas arbitrariamente (NASCIMENTO, 2008).

A ergonomia como ciência trata de desenvolver conhecimentos sobre as capacidades, limites e outras características do desempenho humano que se relacionam com o projeto de interfaces, entre indivíduos e outros componentes do sistema, segundo Moraes e Mont'Alvão (2000), citado por Reitz, Amaral e Cybis (2008). Seus indicadores usabilidade e acessibilidade possibilitam a maioria dos usuários uma navegação acessível e confortável. Para Galvão Filho e Damasceno (2008), no mundo virtual, a acessibilidade é representada por sites que possibilitam à maioria das pessoas a compreensão do seu conteúdo, independentemente das suas limitações físicas ou do equipamento que estão utilizando para navegar pela internet.

As características de qualidade de um website, segundo Oliveira, Brito e Campos (2004), sob enfoque da facilidade de uso, são: inteligibilidade, apreensibilidade, interatividade, atratividade, disponibilidade de auxílios, facilidade de localização da informação, acessibilidade, facilidade de impressão, download e comunicação.

A inteligibilidade de um website é fornecida pelos atributos que evidenciam o esforço do usuário para reconhecer seu conceito lógico e sua aplicabilidade. Enquanto o esforço do usuário para aprender sua aplicação é a apreensibilidade. Já a interatividade refere-se à característica de manutenção de diálogo conciso e claro entre o usuário e a interface. Como atratividade entende-se a característica do sistema de utilizar recursos multimídia (som, imagem e texto) que despertem o interesse do usuário e prendam sua atenção. Outra característica de qualidade, sob enfoque da usabilidade é a disponibilidade de auxílios, característica de o sistema possuir links para informações de ajuda disponíveis para seus usuários. A facilidade de localização das informações refere-se às características existentes no sistema que possibilitam, com facilidade, a localização dos diferentes assuntos pelos usuários (envolve ferramentas de busca, mapa do site, FAQ etc.). Falamos em acessibilidade quando nos referimos às características do sistema de apresentar facilidade para utilização por usuários que não dispõem de todos os recursos tecnológicos (última versão de browsers, visualização de imagens etc.). Já as características de facilidade de impressão, download e comunicação, permitem, respectivamente, a impressão de suas páginas de forma correta e com 
facilidade, sem a necessidade de configurações extras, a transferência de informações da web para seu próprio computador e a existência de canais de comunicação entre o usuário e os desenvolvedores responsáveis.

\section{Metodologia}

As características dos usuários e da instituição foram os primeiros itens a serem investigados e, logo após, considerou-se o planejamento da interface. A construção do website seguiu três etapas sequenciais: a seleção do conteúdo; o desenvolvimento e implantação, e a avaliação.

\section{Seleção do Conteúdo}

Com o desenvolvimento do website institucional para a escola, pretendeu-se disponibilizar um instrumento de apoio aos afazeres educacionais de todos os componentes da comunidade escolar. O fornecimento da informação atualizada é necessário para o bom desenvolvimento das atividades dos professores, dos alunos e dos demais servidores. Alguns exemplos destas informações são: grades curriculares, horários, calendários escolares, regras, datas importantes etc. (Figura 1). O website apresenta a informação em múltiplos formatos, como imagens, sons, filmes e textos, sendo suas principais características a hipertextualidade (acesso a informações interconectadas) e a interatividade (capacidade de "diálogo" entre o computador e o usuário).

Figura 1 - Mapa conceitual do levantamento dos itens relevantes para a construção do website da ETESED

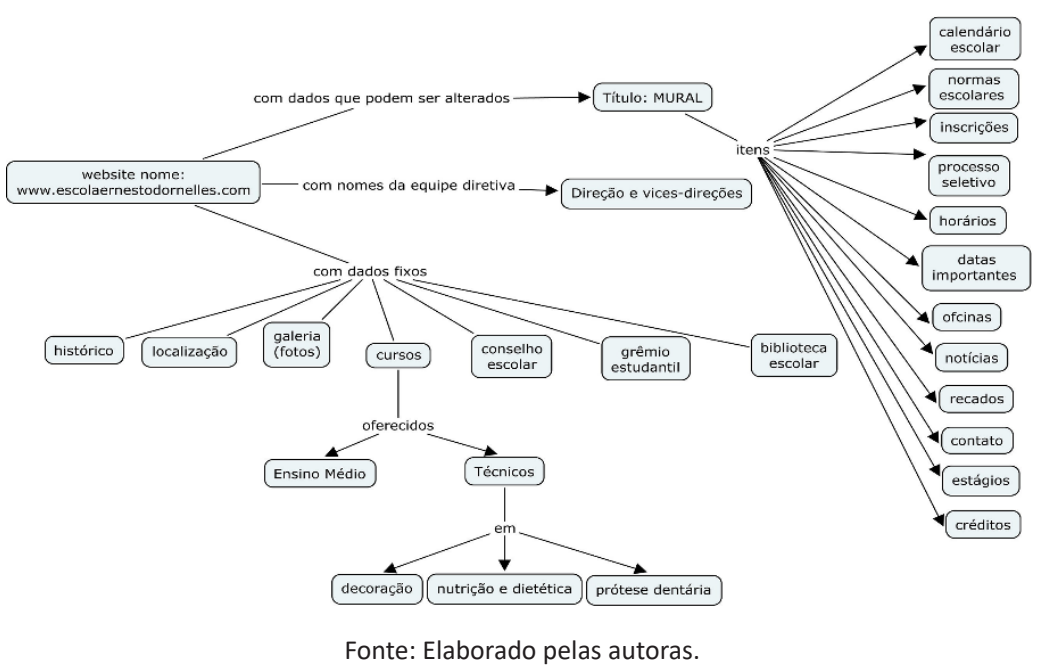

Os elementos multimídia utilizados no website foram aqueles adequados às necessidades e limitações dos seus usuários. Nos textos, na sua maioria curtos para evitar a fadiga causada pela leitura na tela do computador, foram empregadas letras do tipo Verdana de tamanho 10, com títulos e subtítulos em negrito. Detalhes importantes do texto tiveram um tamanho de letra maior: entre 14 e 16. Os textos maiores, como a biografia do Senador Ernesto Dornelles e o histórico da escola, tiveram alinhamento justificado para facilitar a impressão para feitura de trabalhos.

As imagens utilizadas no website dividem-se em fotografias e ícones, as primeiras representam os integrantes da escola em suas atividades, detalhes da arquitetura da escola e de eventos dignos de nota; os ícones representam as entidades relacionadas com o cotidiano da escola, que foram utilizados como botões que remetem para as páginas respectivas. Foram também utilizados 
ícones animados, de formas simples, para ressaltar os eventos importantes para os diferentes períodos escolares.

\section{Desenvolvimento e Implementação}

A primeira versão do website institucional da ETESED consistiu em um conjunto de páginas em linguagem html, com navegação orientada em blocos, onde a página principal apresentava links em títulos e ícones, que remetiam o usuário a outras páginas de interesse e informação do usuário. Nestas, os links poderiam promover o retorno à página inicial ou um deslocamento para páginas anteriores e posteriores, de acordo com a organização da página inicial. Os links foram mantidos na versão atual e, como na primeira versão, direcionam o usuário para páginas e conteúdos em formato pdf. Assim como os botões, que encaminham o usuário para websites de interesse da comunidade. Como indicadores de qualidade do design para a construção e análise do website, foram usadas as cores e os elementos multimídia (textos, animações, imagens estáticas, sons e vídeos). No design, foram ressaltadas as características da arquitetura, e a cor de fundo escolhida (rosa) era a cor original do prédio. Assim, no website, as cores procuraram reforçar a proposta educacional, e todo cuidado foi dispensado na escolha da cor de fundo para que não reduzisse a legibilidade do texto e permitisse a impressão. A cor escolhida identifica rapidamente a escola. As páginas acessadas seguiram o plano básico da interface da página inicial, com a mesma cor de fundo e detalhes de fotografias no topo da página.

A interface, baseada em menus, incluiu duas colunas. A primeira coluna apresentava itens que fazem parte da estrutura funcional da escola e que não mudam tão frequentemente: equipe diretiva, histórico, localização, galeria, biblioteca, cursos de ensino médio, cursos técnicos de Decoração (atualmente, Design de Interiores), de Nutrição e Dietética e de Prótese Dentária, Conselho Escolar, Grêmio Estudantil e um link para uma página do Google grupos - Grupo: Escola Ernesto Dornelles, de livre acesso e participação. A segunda coluna, denominada mural, continha assuntos que apresentam mudanças mais frequentes: calendário escolar, normas escolares, inscrições, processo seletivo, horários, datas importantes, cursos de informática, notícias, recados, contato, estágios e créditos.

Os princípios de ergonomia foram observados e aplicados em todos os critérios, e o website foi desenvolvido de maneira a oferecer uma interface diversificada, de fácil navegação e compreensão, sem limitação quanto ao equipamento, versão do Browser e resolução do monitor, assegurando a acessibilidade do mesmo. Para tanto o idioma usado no site está especificado no seu código-fonte, e a maioria das imagens da página contém um texto descritivo, permitindo-se a acessibilidade de cegos. É possível a visita ao site por meio de um tablet, smartphone ou outro aparelho com tela reduzida, navegando-se confortavelmente por ele. Dentre os aspectos ergonômicos, foram desenvolvidos aqueles considerados gerais de usabilidade e acessibilidade. A usabilidade como medida da qualidade do website, entendida como da ordem de facilidade de comunicação, divulgação de informações e material didático, tornando-o um espaço virtual que possibilite a aprendizagem à distância e intercâmbio entre os indivíduos deste contexto de forma cooperativa.

$\mathrm{Na}$ construção do website, foram evitados elementos multimídia pesados, tornando-o acessível e rápido, o que possibilita o uso de conexão lenta para acessar a Internet. A navegação via teclado inclui o público com limitações físicas ou de coordenação motora, impossibilitados do uso do mouse.

Para a implantação do website, foi utilizada a oferta de hospedagem do provedor de Internet da escola, o UOL. Através do cadastramento e escolha do nome de registro, pôde-se baixar os arquivos e hospedar a página. 
A avaliação consistiu na coleta de informações através de aplicação de questionário com itens fechados e distintos para cada grupo, com o objetivo de promover um levantamento no que se refere às características de qualidade, sob enfoque dos critérios de navegação, design e ergonomia do website escolar.

A graduação para a avaliação dos indicadores relacionados nas questões foi: 0 - Extremamente negativo(a), 1 - Negativo(a), 2 - Mediamente positivo(a), 3 - Positivo(a), 4 - Muito positivo(a).

A avaliação de percentuais para a soma das graduações positivas e muito positivas apresentadas pelos indicadores, seguiu os seguintes intervalos com respectivos conceitos: $0 \%-30 \%$ Insuficiente, 30\% - 50\% Regular; 50\% - 70\% Bom; 70\% - 100\% Muito bom.

Escolheram-se dois grupos de avaliadores com diferentes perfis: o primeiro grupo (1) foi composto por professores e demais servidores, e o segundo grupo (2), por alunos, sendo que cada grupo continha 12 integrantes.

\section{Resultados e Discussão}

A primeira versão (Figura 2a), foi utilizada do ano de 2008 a 2010 e foi avaliada. Já a segunda (Figura 2b) foi utilizada de 2010 a 2014. Ambas foram construídas pelo autor. Os questionários de avaliação encontram-se em Borges (2008).

Figura 2 - a) Imagens da página inicial do website da Escola Técnica Estadual Senador Ernesto Dornelles 1ạ versão (2008-2010). b) 2a versão (2011-2014). Autor - Professora da Escola.

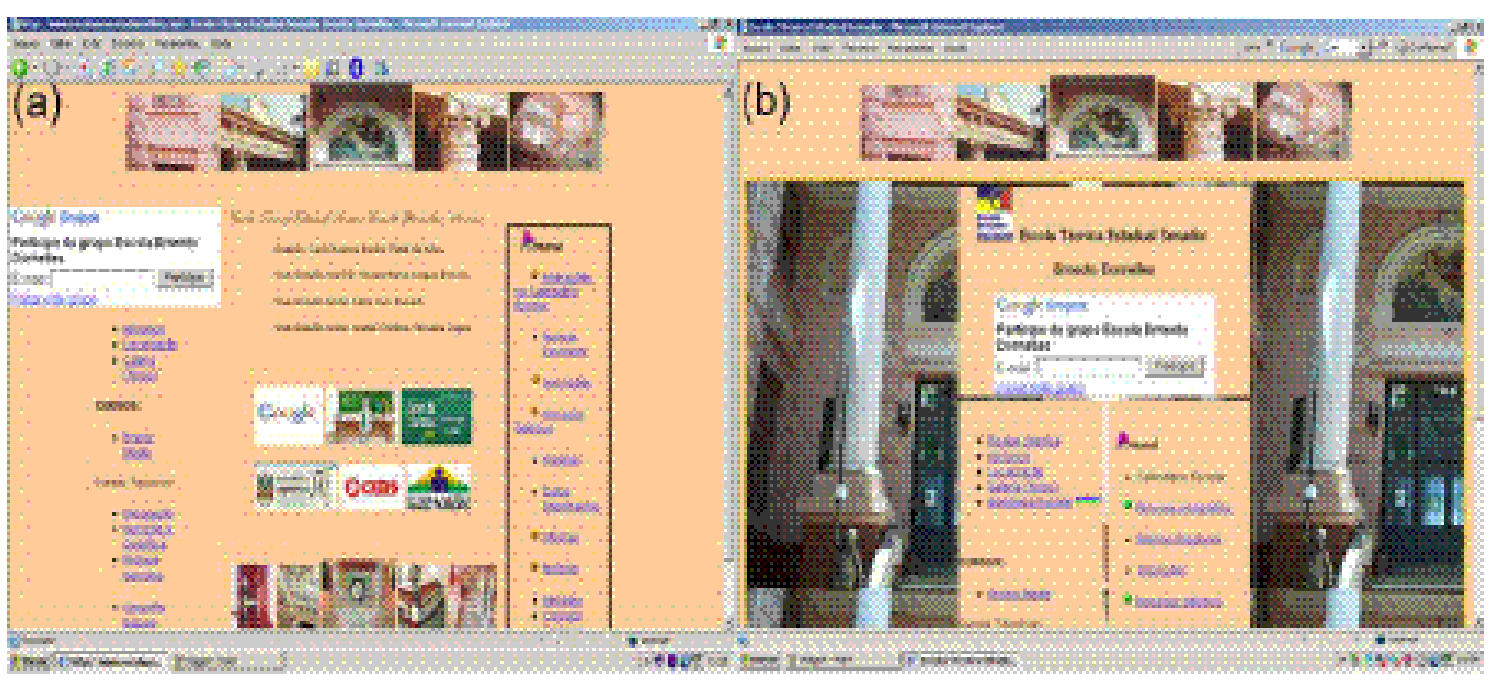

Fonte: Elaborado pelas autoras.

\section{Navegação - 1ạ versão}

A partir da pesquisa bibliográfica chegou-se aos seguintes indicadores para o critério de navegação, utilizados na construção das questões do questionário: a facilidade de deslocamento, de aprendizagem do deslocamento, de entendimento dos modos de navegação, de sinalização, se é gratificante, prazeroso ou cansativo navegar pelo website.

O grupo 1, representado pelos professores e demais servidores da escola e o grupo 2, pelos alunos, apresentaram, respectivamente para o critério de navegação, percentuais de $79 \%$ e $85 \%$ de respostas muito positivas e positivas para suas questões. Com este resultado (Figura 3) acredita-se 
que os indicadores de navegação aplicados no website, foram utilizados de maneira apropriada, agradando a maior parte dos componentes dos grupos 1 e 2 .

Figura 3 - Gráficos percentuais da graduação, do total de respostas para indicadores de navegação, grupos 1 e 2.

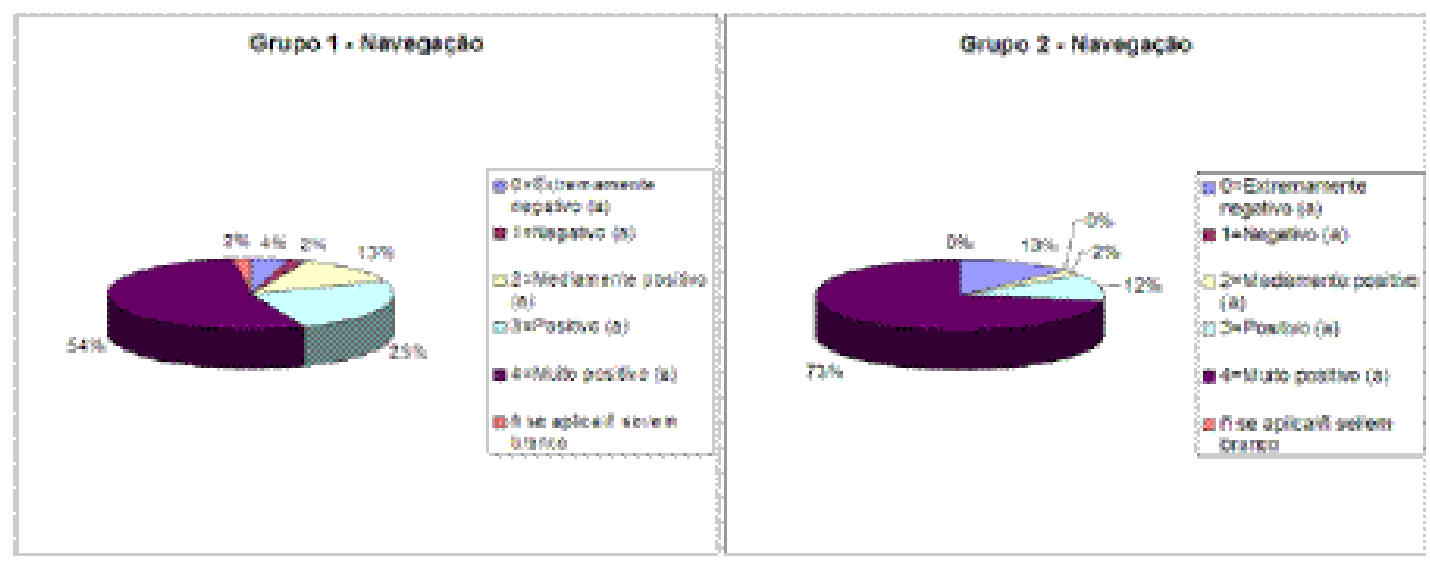

Elaborado pelas autoras.

\section{Design - 1a versão}

Para o design os parâmetros considerados foram: se o website é atraente, se o nome do website é adequado, se é fácil encontrar ajuda, a organização dos itens, se foram levadas em conta as características dos usuários, se as imagens, vídeos e sons são agradáveis e a organização das informações.

Os grupos 1 e 2, representados pelos professores e demais servidores da escola e pelos alunos, apresentaram, sobre o critério de design, percentuais de $82 \%$ e $88 \%$ de respostas muito positivas e positivas para as questões, com este resultado (Figura 4) acredita-se que os indicadores de design aplicados no website, foram utilizados de maneira apropriada, agradando a maior parte dos componentes dos grupos 1 e 2 .

Figura 4 - Gráficos percentuais da graduação do total de respostas para indicadores de design, grupos 1 e 2 .

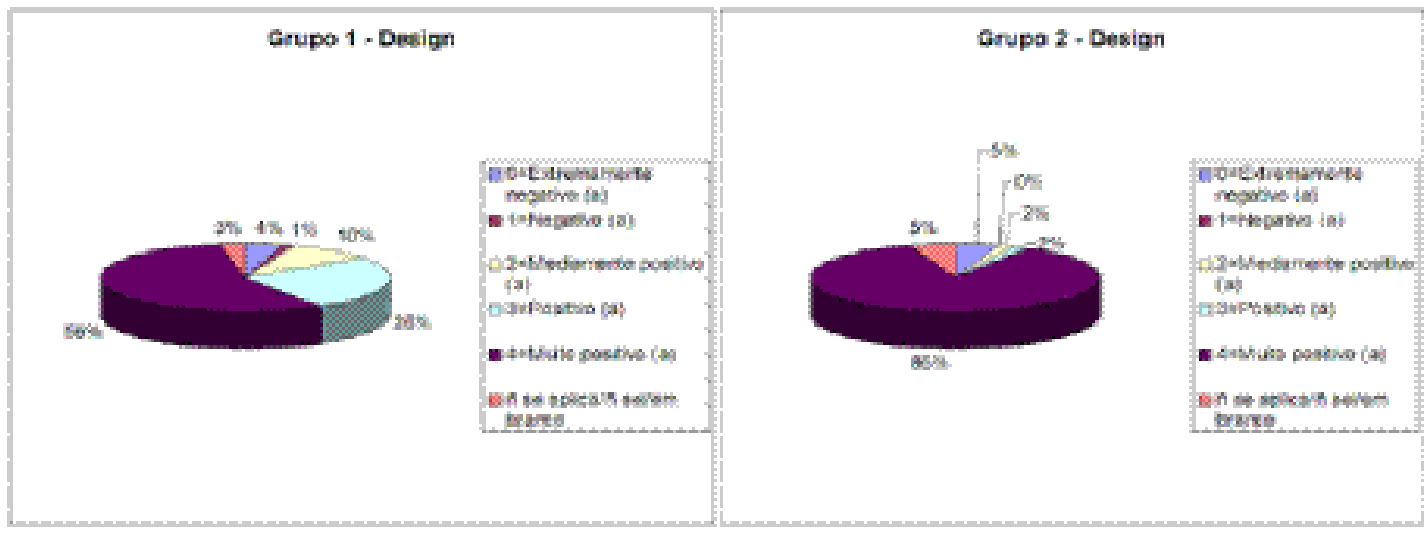

Fonte: Elaborado pelas autoras. 


\section{Ergonomia - 1a versão}

A pesquisa bibliográfica forneceu os seguintes indicadores para o critério de ergonomia (usabilidade e acessibilidade), que foram utilizados na construção das questões do questionário: visualização dos textos e imagens, download, atualização, impressão, se oferece ajuda, se oferece a fonte das informações fornecidas no website, se os textos são curtos, diretos, fáceis de entender e de ler e se é oferecido endereço de contato com o(a) encarregado(a) pela manutenção do website.

Os dois grupos, o de professores e demais servidores da escola (1) e o grupo formado pelos alunos (2), apresentaram, para o critério de ergonomia, percentuais de $73 \%$ e $64 \%$ de respostas muito positivas e positivas para suas questões. Com este resultado (Figura 5) acredita-se que os indicadores de ergonomia aplicados no website, foram utilizados de maneira apropriada, agradando a mais da metade dos componentes dos grupos 1 e 2 .

Alguns indicadores foram considerados de desenvolvimento regular e insuficiente. O grupo 1 (professores e demais servidores da escola) julgou como regularmente desenvolvidos a presença de sistema de fórum, chat ou lista de discussão e de integração com ambiente virtual de aprendizagem. O oferecimento de ajuda foi ponderado como insuficientemente desenvolvido.

Para o grupo 2 (alunos), os indicadores regularmente desenvolvidos foram o oferecimento de ajuda e da opção de contato com a equipe de manutenção do site, atualização e opção de download.

Figura 5 - Gráficos percentuais da graduação, do total de respostas para indicadores de ergonomia, grupos 1 e 2.

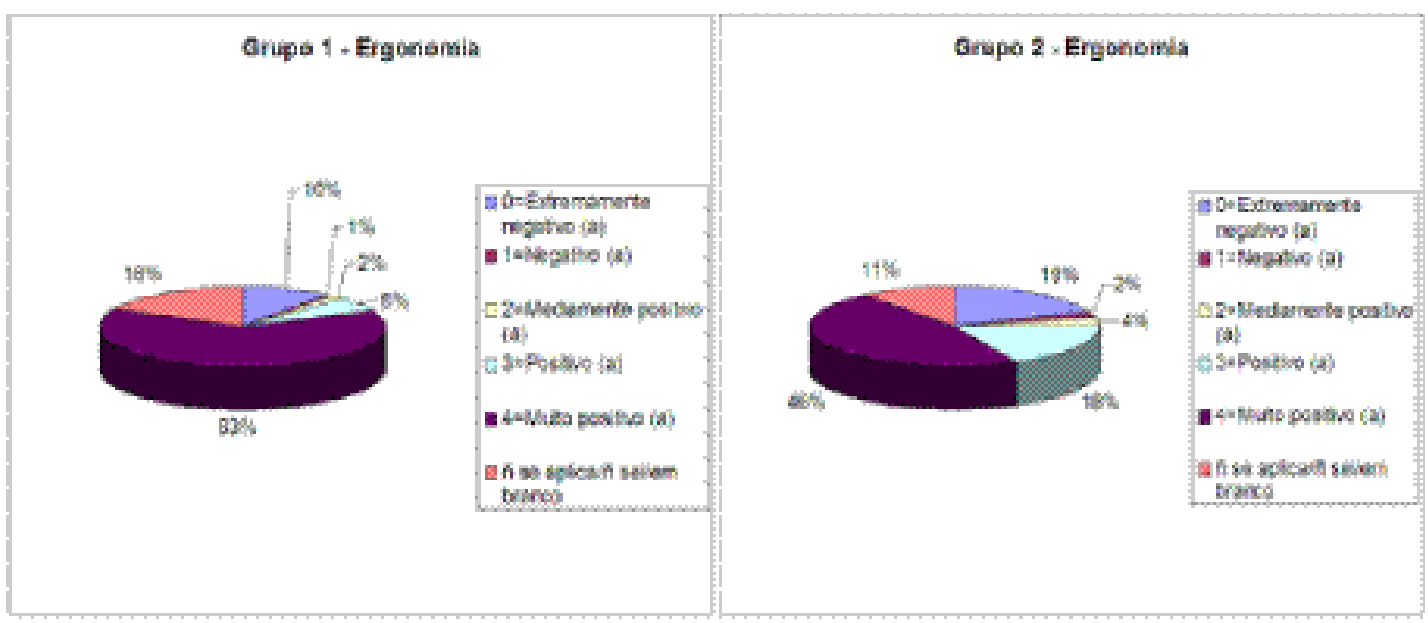

Fonte: Elaborado pelas autoras.

Atualmente o website encontra-se em sua terceira versão (Figura 6), com design semelhante à primeira versão e criado no construtor gratuito de sites WIX.com ${ }^{\circ}$. A versão atual guarda sua organização original, como modificações na disposição dos elementos da página e no fundo da página. 


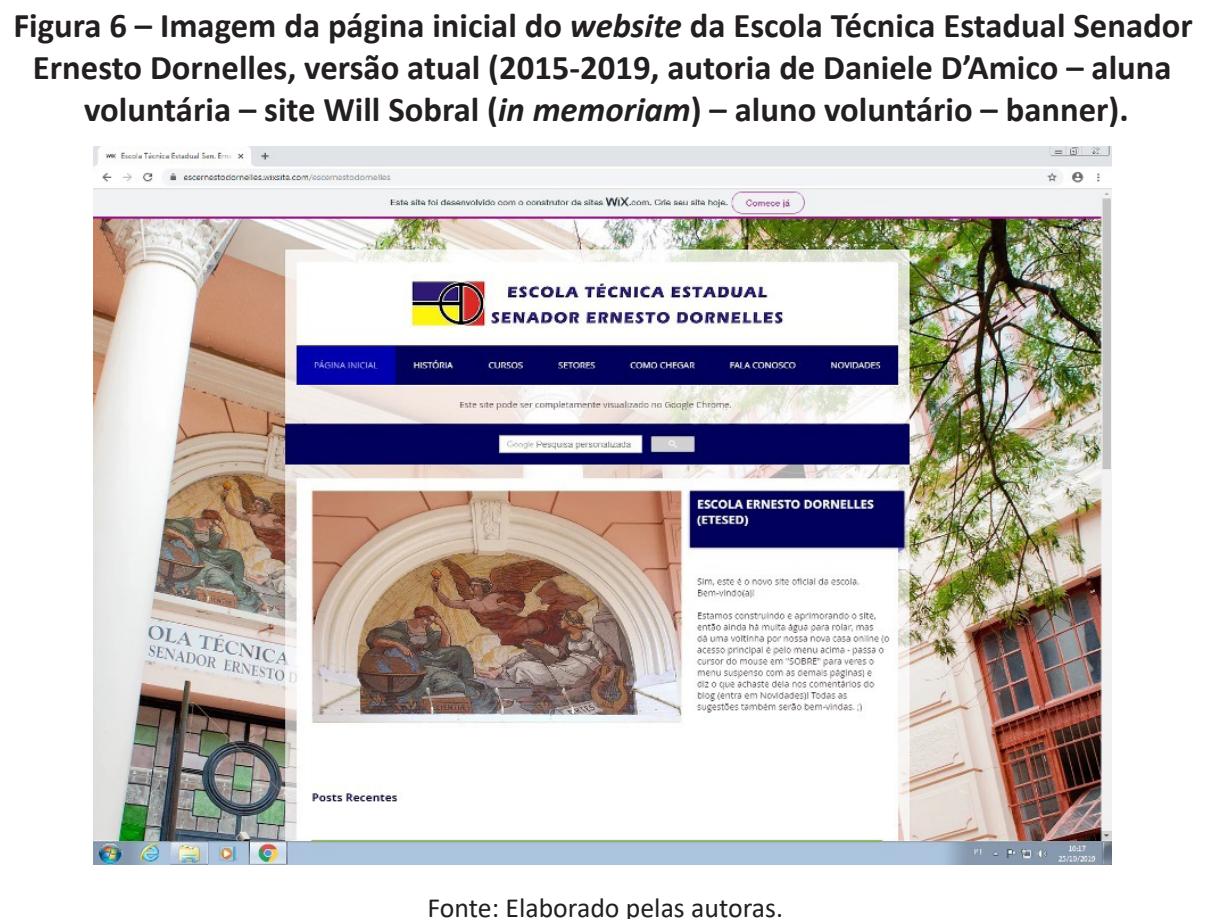

\section{Considerações finais}

Os resultados positivos apresentados na avaliação da construção da primeira versão do website da ETESED são fruto de um projeto que se baseou em bibliografia pertinente e da realização das seguintes etapas: pesquisa sobre o público-alvo, construção e avaliação da ferramenta.

$\mathrm{Na}$ avaliação do website, foram utilizados os critérios de navegação, design e ergonomia, $\mathrm{e}$ seus indicadores foram avaliados positivamente por mais da metade dos membros dos dois grupos. O grupo 1 foi representado pelos professores e demais servidores da escola, e o grupo 2, pelos alunos.

Contudo o fornecimento da opção de download foi avaliado negativamente pelos alunos e dividiu-se entre o positivo e muito positivo entre os professores e demais servidores, devido ao desconhecimento por parte da maioria dos alunos de que os arquivos em pdf poderiam ser baixados e salvos no computador do usuário.

A análise do item "sistema de fórum, chat ou lista de discussão" pelos professores e demais servidores da escola obteve respostas igualmente distribuídas em "não se aplica", em "muito positivo" e em "muito negativo", sugerindo, respectivamente, a constatação, a aprovação e a reprovação da sua inexistência. Apesar disso, um sistema de lista de discussão foi posteriormente desenvolvido no website.

Atualmente na sua segunda versão, o website continua sendo um elo muito importante que une as equipes e os setores de informação da escola com os usuários, disponibilizando aos professores informações pertinentes ao bom desenvolvimento de seu trabalho, como horários e turmas, e aos alunos, futuros e ex-alunos, a informação sobre datas de matrículas, inscrições, horários, cursos de informática, datas importantes, além da informação necessária sobre a escola, desde o histórico às características dos cursos oferecidos. 


\section{Agradecimentos}

À ETESED, na pessoa da diretora Lesli Tietê, pelo convite (construção do website). Aos professores, demais servidores e alunos da ETESED (2010-2014).

\section{Referências}

BORGES, Eliane de Oliveira. Construção de um Website Institucional: um estudo de caso baseado em critérios de navegação, design e ergonomia. 2008. Monografia (Especialização em Informática na Educação) - CINTED, Universidade Federal do Rio Grande do Sul, Porto Alegre, 2008.

GALVÃO FILHO, Teófilo A. e DAMASCENO, Luciana L. As novas tecnologias e a Tecnologia Assistiva: utilizando os recursos de acessibilidade na educação especial. In: CONGRESSO IBERO-AMERICANO DE INFORMÁTICA NA EDUCAÇÃO ESPECIAL, 3., 2001, Fortaleza. Anais [...]. Fortaleza: MEC, 2002.

MORAES, Anamaria de; MONT’ALVÃO, Claudia. Ergonomia: conceitos e aplicações. 2. ed. Rio de Janeiro: Ed. 2AB, 2000.

NASCIMENTO, Anna Christina de Azevedo. Princípios de design na elaboração de material multimídia para a Web. [S. l.]: MEC, 2008. Disponível em: http://www.vdl.ufc.br/aprendizagem_mediada/cofre/principios\%20de\%20design\%20 de\%20multimidia.pdf. Acesso em: 15 abr. 2019.

OLIVEIRA, Káthia Marçal; BRITO, Mirian Cristiane Alves; CAMPOS, Renato Jorge Silva. Avaliação de um software educacional na web.Colabor@, Curitiba, v. 2, n. 6, p. 1-13, 2004.

REITZ, Doris Simone; AMARAL, Fernando Gonçalves, CYBIS, Walter de Abreu. Abordagem Ergonômica de Avaliação de Websites no âmbito da Educação à Distância. Renote, Porto Alegre, v. 2, n. 2, nov. 2004. Disponível em: https://seer. ufrgs.br/renote/article/view/13683/9936. Acesso em: 23 ago. 2008.

VASCONCELOS FILHO, José Eurico de. Um modelo de suporte ao design baseado no rationale: relacionando espaço de problema ao espaço de solução no design. 2010. Tese (Doutorado em Informática) - Pontifícia Universidade Católica do Rio de Janeiro, Rio de Janeiro, 2010.

VYGOTSKY, Lev Semionovitch. Formação Social da Mente. São Paulo: Martins Fontes, 1998.

Data de submissão: 29/10/2019

Data de aceite: 16/07/2020 